\title{
A TEORIA ATOR-REDE EM UMA SEQUÊNCIA DIDÁTICA PARA DISCUSSÃO DO TEMA ECOSSISTEMAS E SUAS TRANSFORMAÇÕES
}

\author{
THE ACTOR-NETWORK THEORY IN A DIDACTIC SEQUENCE FOR \\ DISCUSSION OF THE THEME ECOSYSTEMS AND THEIR \\ TRANSFORMATIONS
}

\author{
Fernanda Costa dos Santos Dressler ${ }^{1}$ \\ Fábio Augusto Rodrigues e Silva ${ }^{2}$ \\ Danilo Seithi Kato ${ }^{3}$
}

\begin{abstract}
Resumo: Este estudo se fundamentou na teoria ator-rede e investigou processos de ensino e aprendizagem no $6^{\circ}$ ano do Ensino Fundamental de uma escola pública em Belo Horizonte a partir de uma sequência didática que discute sobre ecossistemas e suas transformações. Tomamos esse processo como uma prática sociomaterial em que a aprendizagem decorre de um processo de associação entre humanos, artefatos naturais e tecnológicos construídos por meio de uma rede de múltiplos fatos, objetos e pessoas e nos dedicamos a responder: Como o conhecimento sobre o ecossistema e suas transformações é mobilizado por meio de um conjunto de atividades em uma sequência didática, das quais se destaca uma trilha ecológica? Em nossos resultados, constatamos que as atividades possibilitaram uma experiência que abarca aspectos e assuntos que envolvam o sujeito e seu entorno, caracterizado-se como uma "aprendizagem estética", o que propicia uma educação científica que amplia percepções sobre ambiente dos estudantes.
\end{abstract}

Palavras-chave: Aprendizagem Estética; Teoria Ator-Rede; Ensino Fundamental II.

Abstract: This research consists of a study based on the actor-network theory to investigate the teaching and learning processes with 6th-grade students from a public school in Belo Horizonte from a didactic sequence that discusses ecosystems and their transformations. We adopted this educational method as a socio-material practice in which learning results from a process of association between humans, natural and technological artifacts built through a network of multiple facts, objects, and people. From this direction, we dedicate ourselves to answer: How is knowledge about the ecosystem and its transformations mobilized through a set of activities in a didactic sequence, of which an ecological trail stands out? In our results, we found that the didactic sequence enabled an experience that encompasses aspects and subjects that involve the subject and his surroundings, characterized as "aesthetic learning", which provides a scientific education that expands students' perceptions about the environment.

Keywords: Learning Aesthetic; Actor-Network Theory; Elementary School.

\footnotetext{
${ }^{1}$ Licenciada em Ciências Biológicas pela Instituto Metodista Izabela Hendrix (IMIH). Mestre em Ensino de Ciências pela Universidade Federal de Ouro Preto (UFOP), Ouro Preto, Minas Gerais, Brasil. E-mail: fernandac.biologia@gmail.com

${ }^{2}$ Doutor em Educação pela Universidade Federal de Minas Gerais. Professor do Mestrado em Ensino de Ciências da Universidade Federal de Ouro Preto (UFOP), Ouro Preto, Minas Gerais, Brasil. E-mail: fabogusto@gmail.com

${ }^{3}$ Doutor em Educação pela Universidade Estadual Paulista (UNESP). Professor do Mestrado em Educação da Universidade Federal do Triângulo Mineiro (UFTM), Uberaba, Minas Gerais, Brasil. Email: danilo.kato@uftm.edu.br
} 


\section{Introdução}

DOI: https://doi.org/10.33238/ReBECEM.2020.v.4.n.2.24220

Essa pesquisa foi realizada a partir de um processo de construção e avaliação de uma sequência didática sobre ecossistemas urbanos e suas transformações que incluía o estudo do meio como uma das atividades a serem desenvolvidas em uma turma do Ensino Fundamental II. Essa investigação foi apresentada em uma dissertação de mestrado profissional desenvolvida no Programa de Pós-Graduação em Ensino de Ciências da Universidade Federal de Ouro Preto (MPEC/UFOP) (SANTOS, 2017). O nosso interesse por essa metodologia didática se justifica por entendermos que a mobilização de alunos para diferentes ambientes pode propiciar um contato mais próximo com os elementos relacionados aos conteúdos socioambientais que são estudados nas aulas de ciências.

Lestinge e Sorrentino (2008) definem o estudo do meio como qualquer estratégia de ensino que coloca os estudantes e professores em contato com um ambiente a ser estudado, seja ele natural ou social. Esse ambiente substitui a sala de aula, e pode propiciar um trabalho diferenciado sobre os mais diferentes assuntos, seja ambientais, tecnológicos, científicos, sociais ou culturais. O estudo do meio oportunizaria a transformação no olhar dos sujeitos que desenvolveriam uma análise mais crítica, reconhecendo uma realidade dinâmica e complexa. E ainda, despertaria sensações e sentimentos que fomentariam a atuação das pessoas em prol da coletividade (LOPES; PONTUSCHKA, 2009; LESTINGE; SORRENTINO, 2008).

Quando planejamos a nossa sequência didática ${ }^{4}$, estabelecemos que utilizaríamos a trilha em uma estação ecológica que fica na mesma cidade da escola, foco de nossa atuação nessa pesquisa. Acreditávamos que essa trilha poderia proporcionar o contato dos alunos com um ecossistema que possui características próximas ao que estava presente antes do processo de urbanização que ocorreu na região da escola ou próximo à casa desses estudantes. Esperavámos criar oportunidades para que esses estudantes percebessem o processo de transformação gerado pela comunidade a que pertencem, processos que muitas vezes se perdem na história e são desconhecidos pela maioria dos habitantes de uma determinada região. Nesse sentido, estabelecemos como problema de pesquisa: Como o conhecimento sobre o

4 A sequência didática pode ser acessada no Repositório Institucional da UFOP: http://www.repositorio.ufop.br/handle/123456789/9004 
DOI: https://doi.org/10.33238/ReBECEM.2020.v.4.n.2.24220

ecossistema e suas transformações é mobilizado por meio de um conjunto de atividades das quais se destaca uma trilha ecológica?

Ressaltamos que, em geral, as atividades em trilhas são baseadas na interpretação e na aquisição de informações sobre o ambiente que se observa (SOUZA et al., 2012). Esses processos podem favorecer uma aprendizagem estética que permita apreciar, valorizar ou julgar determinada situação ou fenômeno socioambiental (FLANNERY, 1999). Além disso, os estudos do meio podem ser planejados para que os estudantes possam se deparar com problemas controversos que perpassam as questões ambientais e que se relacionam a conservação, preservação e manejo de unidades de conservação (SILVA; CARVALHO, 2007; SANTOS, et al., 2011; COUTINHO; MATOS; RODRIGUES E SILVA, 2014). Cientes dessa possibilidade, procuramos aproximar a nossa pesquisa da Abordagem Ciência, Tecnologia, Sociedade e Ambiente (CTSA).

Essa aproximação se deu por meio de uma leitura mais crítica sobre os sentidos que permeiam o movimento CTSA e que criam uma míriade de compreensões e iniciativas (SILVA et al., 2019). Algumas dessas abordagens são mais limitadas e mais apolíticas e atribuem as decisões aos que dominam os conhecimentos científicos e tecnológicos. Essas abordagens restrigem a discussão aos conhecimentos dos fatos, mas não engendram situações de ensino que mobilizam os alunos à uma discussão mais aprofundada que os possibilitem participar dos processos de tomada de decisão ou enfrentamento dos problemas. Em contrapartida, temos atualmentes outras abordagens mais críticas que se preocupam em oferecer uma análise mais ampla, pois defendem que aspectos históricos, sociais, políticos e econômicos também são imprescindíveis para se identificar, refletir e resolver problemas tecnocientíficos ou ambientais (PEDRETTI; NAZIR, 2011), o que pode contribuir para uma participação mais efetiva na comunidade.

Para construir uma linha de pensamento mais ampla e que nos permitiria entender como se dão as relações CTSA em uma dimensão híbrida, utilizamos como referencial teórico-metodológico: a Teoria Ator-Rede (TAR) (LATOUR, 2012). Por meio da TAR buscamos também compreender como se dá o processo de aprendizagem a partir de mobilizações dos elementos, denominados de $\operatorname{actantes}^{5}$, humanos e não-

\footnotetext{
${ }^{5}$ Actante é considerado como tudo que tem ação (LATOUR, 2012). Os actantes podem ser representados por pessoas, e também por não humanos, tais como: máquinas, animais, plantas, laboratórios, textos, artefatos tecnológicos etc (SAYES, 2014).
} 
DOI: https://doi.org/10.33238/ReBECEM.2020.v.4.n.2.24220

humanos, que se revelaram no decorrer na aplicação da sequência didática e que podem exercer ou sofrer algum tipo de ação ${ }^{6}$. Ao utilizar a TAR como arcabouço de nossas análises, buscamos compreender que cada pessoa tem suas aprendizagens ligadas à uma rede $^{7}$ que se sustenta e é produzida por uma associação entre actantes (híbridos ${ }^{8}$ ) (MELO, 2011).

Portanto, neste artigo procuramos desenvolver um estudo teoria ator-rede pelo qual nos dedicamos a identificar e também descrever a agência dos actantes que participaram dos momentos de aprendizagem possibilitados por algumas das atividades desenvolvidas, com destaque para o estudo do meio, ou seja, a trilha ecológica. Com essa descrição densa, conforme proposta por Latour (2012), evidenciamos a ação dos actantes que nos propicia abordar as contribuições da sequência como um artefato sociotécnico que mobiliza os alunos, sujeitos dessa pesquisa.

\section{Desenvolvendo um estudo teoria ator-rede}

A sequência didática foi produzida com o propósito de oferecer um produto educacional diferenciado para se abordar questões ambientais nas aulas de ciências e foi dividida em três momentos (QUADRO 1). Para a saída de campo na trilha da Estação Ecológica, foi necessário um turno completo, uma vez que a hora/aula de cinquenta minutos não seria suficiente. Toda a sequência foi aplicada pela primeira autora deste artigo que naquele momento era a professora de ciências da turma. Ela assumiu as aulas durante o período de licença saúde da professora que iniciou o ano com esses estudantes.

Quadro 1: Visão geral da Sequência didática aplicada

\begin{tabular}{|l|c|l|}
\hline \multicolumn{3}{|c|}{ SEQUÊNCIA DIDÁTICA } \\
\hline MOMENTOS & $\mathbf{N}^{\mathbf{0}}$ DE AULAS & ATIVIDADES \\
\hline $\mathbf{1}^{\mathbf{0}}$ & 3 & $\begin{array}{l}\text { Aula expositiva sobre o tema: Conservação dos Ambientes; } \\
\text { Exposição de imagens em PowerPoint }\end{array}$ \\
\hline $\mathbf{2}^{\mathbf{0}}$ & 5 & Saída de campo: Trilha na Estação Ecológica da UFMG \\
\hline
\end{tabular}

6 Essa teoria, também conhecida como "sociologia da translação" (LATOUR, 2012) enuncia que o conhecimento é um produto social, em outras palavras, é o resultado de uma associação entre humanos, artefatos naturais e tecnológicos construídos por meio de uma rede heterogênea de fatos, objetos e pessoas (LAW, 1992), ou seja, procura compreender as coisas como efeitos de uma interação em rede. O objetivo da TAR é manter sob o mesmo patamar de análise elementos humanos e não-humanos evitando uma ideia tradicional da sociologia que tenta separar a realidade em uma visão entre natural e social (MELO, 2011).

${ }^{7}$ Um conceito importante para a TAR é o de redes que deve ser entendido como fluxos, circulações, alianças e movimentos nos quais os actantes envolvidos sofrem constantes interferências (FREIRE, 2006).

${ }^{8}$ Híbridos: palavra empregada para designar tudo que não conseguimos separar de forma ontológica pura (LATOUR, 1994). 


\section{\begin{tabular}{|l|l|l|}
\hline $\mathbf{3}^{\mathbf{o}}$ & 2 & Trilha no Bairro \\
\hline \multicolumn{2}{|c}{ Fonte: Elaborado pelos autores }
\end{tabular}}

A aplicação da SD foi realizada em uma escola estadual da Região Leste de Belo Horizonte, que foi escolhida pelo fato da instituição estar localizada em um bairro que passou por um crescimento desordenado, e que é adjacente à Mata da Baleia, um fragmento florestal que sofre ações antrópicas constantes. Também partimos da premissa que era importante discutir questões de preservação do ambiente com a comunidade escolar, pois a região de mata faz parte da vida dos moradores e de muitos alunos que a circundam no retorno para casa.

A turma que participou da pesquisa pertencia ao $6^{\circ}$ ano do Ensino Fundamental II e a escolha da classe foi baseada no fato de que os assuntos discutidos na sequência didática estarem relacionados a grade curricular desta etapa da educação básica. A turma era composta por 35 alunos, de idade entre 11 e 13 anos. A maioria dos alunos morava em bairros vizinhos à escola e vinha de famílias de baixa renda.

No decorrer do desenvolvimento da sequência didática, os fenômenos observados foram registrados em um caderno de campo. Esse registro era feito pela primeira autora sempre após as atividades, que procurava trazer nos registros tudo aquilo que julgava pertinente e necessário às nossas investigações.

O foco de uma análise de TAR concentra-se em situar como os processos são performados $^{9}$, quem atua e como atua, e como essa atuação pode transformar, influenciar, limitar ou definir a realidade. Este foco propicia investigar o processo de ensino e aprendizagem mobilizado pela sequência didática como uma prática sociomaterial, incorporando também às entidades não-humanas como fundamentais para a compreensão da rede sociotécnica (SAYES, 2014). A SD, proposta por nós, se constitui como um objeto sociotécnico, que nos permite investigar como o conhecimento, compreensões, percepções sobre o ambiente podem ser performados por meio de atividades das quais se destacam as trilhas ecológicas.

Para apresentar essa rede e seus efeitos que se referem ao ensino e aprendizagem, devemos construir narrativas. Segundo Latour (2012), depois de ter identificado os actantes e as suas ações, podemos perceber as mobilizações, os movimentos e transformações. Então, o pesquisador coloca em "teste" o seu trabalho por meio da sua escrita que se configura como a sua descrição do rastreamento das

\footnotetext{
${ }^{9}$ Uma reunião de elementos humanos e não-humanos que mantidos juntas e ligadas por meio de processos de translação, performam uma determinada ação.
} 
DOI: https://doi.org/10.33238/ReBECEM.2020.v.4.n.2.24220

associações. Neste sentido, um "bom" relato textual é aquele que traça uma "rede", uma série de ações, onde cada participante faz algo. Este é o ponto de fazer pesquisa: de recolher e triar o material adquirido para identificar minuciosamente os rastros dos actantes, tentar ver quem estava fazendo o que, como eles estavam fazendo, onde e quando tudo isso estava acontecendo, e por quê. Porém, o que é fundamental, é que para a TAR o trabalho do pesquisador é descrever as associações.

Destacamos que, na construção do nosso relato, que irá apresentar dados sobre o primeiro e segundo momento da $\mathrm{SD}$, nos valemos da produção de diagramas de translações (FARIA; COUTINHO, 2015; ALLAIN, 2015) que mostram as associações e os desvios/novas associações resultantes das translações ocorridas durante os diferentes momentos que foram proporcionados pela sequência didática. Em nossa representação gráfica procuramos demonstrar os deslocamentos de interesses por meio de uma linha vermelha, ora para esquerda que indica os desvios, para direita, indica as associações. Apesar dos desvios distanciarem da proposta inicial da atividade, eles foram importantes para o processo de aprendizagem, pois podem se relevar uma nova associação, até então inesperada entre os actantes. Á medida que a linha se desloca para a direita, no sentido das associações, mais os actantes se conectam e se articulam, caminhando no sentido da proposta inicial de cada momento da aula ou para as expectativas de aprendizagem que esperávamos quando planejamos a sequência didática. Os actantes foram mapeados a partir da análise de cada aula e das impressões relatadas no diário de campo. Sempre que determinado assunto/elemento entrava nas discussões, esse era definido como um actante mediador, pois contribuía com a performance na rede.

\section{A sequência didática e a mobilização dos actantes}

Nesta seção apresentaremos um relato relacionado à algumas etapas do desenvolvimento da SD, descrevendo e analisando os momentos que ocorreram as translações entre os diferentes actantes. É importante destacar que os nomes que surgirem no decorrer de nosso relato são fictícios.

\subsection{Momento 1 - Aula expositiva sobre o tema "A conservação dos ambientes"}

A primeira atividade da sequência começou com a leitura do texto "A importância da diversidade biológica" proveniente do livro didático Construindo 
DOI: https://doi.org/10.33238/ReBECEM.2020.v.4.n.2.24220

Consciência (CARO et al., 2009), e que foi distribuído aos alunos. Inicialmente, conforme o planejamento, foi solicitado que fizessem uma leitura individual para um primeiro contato, no entanto essa tarefa não saiu conforme planejado. Eram muitos estudantes na mesma sala, as carteiras muito próximas umas das outras e a tentativa de silêncio foi frustrada. Preocupada com o fato da importância dos alunos terem pelo menos um contato com o texto antes das discussões, a professora fez a leitura oral, insistindo para que prestassem atenção nas informações. Naquele momento, alguns alunos tentavam atentamente ouvir enquanto outros se dispersavam com conversas e brincadeiras.

Após a finalização da leitura perguntou-se aos alunos se eles sabiam qual a importância de preservar a diversidade biológica. Muitos tentaram responder, falando ao mesmo tempo. Após acalmá-los, uma aluna respondeu que "os animais e as plantas eram importantes para a gente". Outros alunos concordaram com a resposta e fizeram vários comentários, que foi impossível defini-los com clareza, pois falavam e conversavam ao mesmo tempo. Com a intenção de instigá-los a responder e ouvir mais o que conheciam sobre o assunto, a professora perguntou: "Por quê?". A mesma aluna da resposta anterior, disse que era "porque os animais e as plantas servem de comida e companhia pra gente". Começaram a falar sobre vários exemplos de animais, dentre eles: de cachorros, de pássaros, cavalos e outros que tinham maior contato. Entretanto, pouco tempo depois os alunos manifestaram desinteresse e desmotivação pela aula, aguardando ansiosamente para o fim do turno.

$\mathrm{Na}$ tentativa de retomar a atenção deles e trazê-los de volta para as discussões sobre o texto, a docente fez mais uma pergunta: "Vocês conhecem alguma unidade de conservação (UC) aqui em BH?’ Perguntaram o que era unidade de conservação, apesar do texto citar e explicar. A professora respondeu que era um espaço com certas características naturais e que é preservado e protegido por lei, e seguiu indagando-os. "Então, vocês conhecem alguma aqui em BH"? Novamente muitos falam ao mesmo tempo. O aluno Bernardo falou que tinha um lugar próximo a Mata da Baleia que a protege. Ele disse que nunca foi, mas disse que lá é vigiado o tempo todo. Outro aluno comentou que mesmo sendo proibido tem gente que coloca fogo, pega madeira, mata animais, joga lixo. Foram feitos muitos comentários a respeito, confirmando que essas ações eram frequentes na região da mata. Nesse momento, foi possível perceber que o aluno Bernardo tinha uma ideia do que era unidade de conservação, mesmo não conseguindo defini-la conceitualmente. Ainda nessas discussões, outro aluno, João, 
DOI: https://doi.org/10.33238/ReBECEM.2020.v.4.n.2.24220

citou o zoológico como unidade de conservação e disse que lá está muito feio, parecia estar mal cuidado. Já a maioria dos alunos disse não conhecer e não sabia do que se tratava uma UC, apesar do texto explicar de forma simples. Essa aula foi interrompida com o fim do turno e os alunos devolveram o texto para dar continuidade na próxima aula.

Numa próxima aula, retomamos as discussões do texto falando novamente sobre a importância de uma UC para a biodiversidade. A aula também não saiu dentro do que era esperado pela professora e conforme o nosso planejamento da sequência didática' o desinteresse era explícito e os alunos estavam sempre perguntando sobre o "passeio" que estaria próximo. Para eles a atividade de campo, na trilha ecológica se tratava de um passeio com o objetivo de recreação. Com a tentativa frustrada de dar continuidade às discussões, a professora pediu aos alunos que fizessem um pequeno comentário em forma de texto sobre o que discutimos na aula anterior. Muitos não haviam compreendido a proposta e interpretaram como se fosse para fazer um resumo do texto que havíamos lido. Foi explicado novamente para alguns que chegaram até a professora, mas continuaram entendendo que era para fazer um resumo e assim o fizeram. Alguns apresentaram pequenas frases em seus textos que aparentemente eram autorais. A seguir são apresentadas algumas transcrições dos textos produzidos.

No texto da aula Vânia escreve que:

[...] Eu já sabia que as capivara, paca e tatus que são, herbívoros continuariam se multiplicando e iriam cada vez mas comer as folhas e quando formos ver, algumas plantas teriam sumido e seria muito ruim para nos que respiramos das plantas e também de animais, por isso devemos lutar para preservar a natureza para que as futuras gerações usufruam dessa natureza $[\ldots]$.

É possível perceber no texto que a aluna está preocupada com os modos alimentares de certos animais. Isso porque em sua concepção as plantas poderiam "sumir" e isso representaria uma grande perda para os humanos, já que dependemos dos vegetais para respirar. No texto ela não aborda nenhum processo metabólico, como a fotossíntese e respiração celular, mas é possível perceber que tem uma ideia sobre tais conceitos, resgatando-os para defender seus argumentos que explicam a importância da diversidade biológica. Além disso, também podemos pensar que os conceitos de cadeia e teia alimentar estariam relacionados às suas ideias.

Já a aluna Karine apresenta ideia de que o lixo dispensado em local inadequado, pode trazer consequências para a comunidade. Apesar de ela não citar no seu texto, evidenciamos dois trechos que expõem a ideia da aluna Karine: 
DOI: https://doi.org/10.33238/ReBECEM.2020.v.4.n.2.24220

[...] eu acho que eles não podem ficar jogando livro nas ruas, boeiros e etc.

$[\ldots]$ " "[...] eu acho que não pode jogar lixo em lugar nenhum, apenas no lugar devido que é o lixo [...].

Além disso, o texto dessa aluna chama atenção para uma segunda ideia, que indica a necessidade de cuidar do espaço em que vivemos para ter um mundo melhor, conforme transcrito abaixo:

[...] Por isso que eu cuido e preservo minha parte pra ter um mundo melhor. Faça igual a mim preserve o seu lugar pra ter um mundo melhor!!.

A frase "[...] preserve seu lugar pra ter um mundo melhor" nos chamou atenção. Isso porque indica que a aluna compreende que "o seu lugar" faz parte de algo mais amplo e que é necessário preservá-lo para melhorar as condições de vida.

Ao analisar este primeiro momento da SD construímos o nosso primeiro diagrama (FIGURA 1), que mostra as associações e os desvios/novas associações resultantes das translações ocorridas durante o primeiro momento da SD.

Figura 1: Diagrama de translações: Leitura do Texto

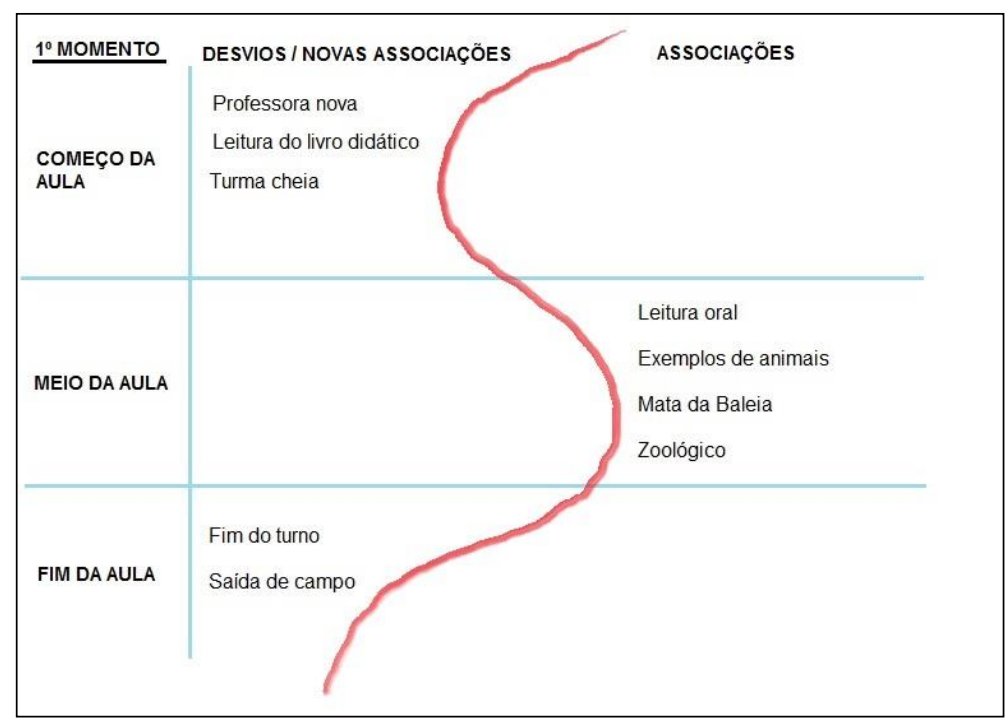

Fonte: os autores

A nossa análise se inicia com a identificação de três actantes que promovem desvios: professora nova, a leitura do livro didático e turma cheia. Vamos ao primeiro ponto, a mudança repentina de uma docente por outra parece ter causado um desequilíbrio no comportamento da turma. Isso pode estar associado à falta de conhecimento da educadora sobre o desenvolvimento dos alunos que propôs uma atividade de leitura que não atraiu o interesse. Destacamos que a incorporação de práticas de leituras de textos em aulas de ciências, não pode ser encarado como uma situação trivial. Silveira Junior, Lima e Machado (2015) defendem que a leitura de 
DOI: https://doi.org/10.33238/ReBECEM.2020.v.4.n.2.24220

textos é essencial para a aprendizagem da linguagem da ciência e ressaltam que a introdução desses materiais deve ser compreendida como uma atividade complexa que exige um planejamento que sustente e dê subsídios para a interpretação dos alunos. Nesse sentido, é essencial o conhecimento sobre o texto e acerca das condições de leitura dos alunos.

Ressaltamos, portanto, que foi muito marcante como um desvio que havia resistência dos alunos para realização da leitura. Quanto à "leitura do livro didático" (texto proposto), nós podemos associá-lo a outro desvio "turma cheia". A sala de aula era pequena para o número total de alunos. As carteiras eram muito próximas propiciando momentos de desatenção devido a constantes conversas, o que também pode ter levado a falta de interesse para com a leitura do texto.

Apesar disso, no momento em que foi realizada a leitura oral do texto pela professora, temos momentos de associação entre professora-texto-estudantes, de forma que estes últimos puderam entrar em contato com as informações contidas no texto além de explicitar suas ideias. Nesse momento, o híbrido "professora-texto" passou a deixar uma marca, se tornou um mediador (LATOUR, 2012), uma vez que as discussões foram geradas em torno dele. A partir disso, alunos, professora e texto começaram a performar interações mobilizando outros actantes que não estavam no texto, um movimento que ultrapassa os limites da sala de aula e se expande para englobar a realidade e vivência de cada um dos alunos (COUTINHO; MATOS; RODRIGUES E SILVA, 2014). Isso gerou uma nova associação tratando de diferentes exemplos de animais que foram transportados para dentro da sala de aula. A partir desses exemplos foi possível inserir e discutir sobre a importância da unidade de conservação em uma cidade, surgindo dessa forma, uma nova associação, a Mata da Baleia, uma região previamente conhecida pelos estudantes, apenas como um local que faz parte do trajeto de ida e retorno da escola, mas que passa a ser articulada de modo diferente neste momento (MELO, 2011). Ao incluírem o zoológico nos comentários, foi possível perceber que houve certa compreensão do termo unidade de conservação. Após alguns comentários sobre o espaço citado os alunos foram novamente desviando do assunto e da rede que se pretendia construir, mas que não se sustentou. No entanto, traçavam novos passos e pareciam construir novas associações, desta vez com a saída de campo. A saída de campo causou bastante motivação e interesse dos alunos, gerando momentos de muita ansiedade. 


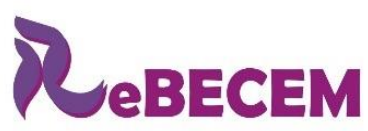

DOI: https://doi.org/10.33238/ReBECEM.2020.v.4.n.2.24220

Em nossas análises, percebemos que o actante pensado inicialmente a partir de nossas previsões como principal, não atuou como tal, uma vez que não foi possível rastreá-lo durante toda a performance da rede. No entanto, ele mostrou certa eficiência ao trazer o termo de unidade de conservação e resgatar elementos naturais para a sala de aula que não estavam presentes. Nesse sentido, acreditamos que seria necessário fazer algumas adequações na atividade, de forma que o texto aumente suas potencialidades para atuar como um actante focal ${ }^{10}$. Ao observarmos o primeiro momento como um todo, percebemos que o texto em si não foi suficiente para deixar rastros ou exprimir uma marca por si só e que isto só foi possível a partir da translação propiciada pela leitura.

\subsection{Momento 1 - Apresentação de imagens de BH}

Essa aula iniciou-se com a montagem do Datashow aparentemente despertando certo interesse dos alunos pelo equipamento, muitos já se ofereciam para ajudar e também para passar os slides. Para dar início a aula foi necessária a organização da turma, mudando a conformação da sala para melhor visualização das imagens que foram projetadas na parede. Começamos a exposição das imagens de Belo Horizonte desde meados de 1900, cada uma com a data e nome do local. À medida que os slides eram trocados, surgiam comentários e discussões a respeito.

Já nos primeiros minutos de aula, os alunos participaram com mais empenho do que na atividade de leitura do texto. As primeiras imagens já causaram certa inquietação em relação às transformações da paisagem belorizontina. A primeira fotografia era da Fazenda do Leitão, local onde se iniciou a construção da capital mineira. Ao vê-la um aluno indagou: "Nossa, mas aí não tem nada". A professora percebeu um espanto. "Nada?" Ela perguntou. "Há uma fazenda, uma casa, ao fundo a imagem da Serra do Curral, que inclusive é possível vê-la daqui da escola. Vocês já viram?” Muitos alunos responderam. "Não, eu nunca vi nada não". Nesse momento os alunos não fizeram uma associação da serra com a história da cidade, desse modo, a serra pode ser considerada um intermediário (LATOUR, 2012).

Seguimos, e a partir do espanto deles em relação as paisagens que estavam vendo a docente fez um comentário "Bom, antigamente, as cidades não eram como conhecemos hoje, ela passou por um projeto, por várias etapas de construção até se

${ }^{10}$ Segundo Callon (1986), actante focal é aquele humano ou não humano que será o principal índice no rastreamento e descrição da rede. Ele pode ser a porta de entrada para a rede que se pretende estudar. 
DOI: https://doi.org/10.33238/ReBECEM.2020.v.4.n.2.24220

tornar o que vemos hoje". Para as próximas imagens foram selecionados locais e pontos que seriam mais conhecidos por estes estudantes, como do centro e da região próxima ao bairro da escola. A ideia era que eles pudessem comparar lembranças que possivelmente guardavam em sua memória. Novamente a diferença na paisagem ia sendo reforçada por comentários do tipo "Mudou muita coisa aqui", "Nossa, mas hoje é muito diferente", "Tinha mais árvores naquela época" e assim por diante.

Os alunos estavam sempre reforçando em relação à quantidade de árvores que havia nas praças, nas ruas e que hoje não tinha mais. Além disso, comentaram sobre a diminuição de árvores e aumento de prédios com o passar dos anos. Também falaram sobre alguns pontos da cidade estarem cercados por grades nos dias atuais e que nas fotos antigas não estavam. Nesse ponto a professora perguntou: "Por quê? O que será que aconteceu que foi necessário a instalação dessas grades, de muros?" Alguns alunos responderam: "por causa de ladrões". Nesta fala tem-se a sensação de que eles percebem que o desenvolvimento urbano e consequente crescimento da cidade levaram ao aumento da insegurança da população.

À medida que ia avançando as imagens, foi possível notar que identificaram as mudanças da paisagem de Belo Horizonte com o passar dos anos. Sempre que surgia uma foto do centro de BH a surpresa era grande, pois na concepção deles aquele espaço estava vazio demais. As experiências que possuem com o local são de um aglomerado de pessoas, comércio movimentado e trânsito pesado. Além disso, à medida que as imagens mostravam fotos mais recentes eles percebiam que as árvores eram substituídas por construções humanas. Ao longo da aula foi percebido que os alunos estavam mais participativos e demonstravam maior interesse em comparação com a aula anterior. Apesar de algumas conversas paralelas, a maioria estava atenta às imagens que iam sendo projetadas, o que ressalta como os diferentes não-humanos, tais como a imagens antigas da construção de uma lagoa, a Lagoa da Pampulha, e de um rio que corta o centro da cidade, Ribeirão Arrudas, os mobilizaram para uma performance diferenciada de interesse e de participação na aula de ciências (FENWICK; EDWARDS, 2012; COUTINHO; VIANA, 2019).

Os discentes comentaram o que mais lhes marcaram é que com o passar dos anos as árvores diminuíram consideravelmente para abrigar maior quantidade de prédios, casas, pessoas e carros. Em uma discussão se falou sobre o quanto é impactante ao ambiente no processo de urbanização e alguns alunos comentaram que essas mudanças eram necessárias para nossa sobrevivência. Estes comentários geraram uma 
DOI: https://doi.org/10.33238/ReBECEM.2020.v.4.n.2.24220

discussão sobre a falta de planejamento de uma cidade, construções mal feitas, as atitudes humanas que prejudicam o ambiente e consequentemente a paisagem natural.

A partir de nossas análises e considerações sobre essa aula, construímos o diagrama das translações que emergiram a partir das associações e desvios entre os actantes (FIGURA 2).

Figura 2: Diagrama de translações: Apresentação das Imagens de BH

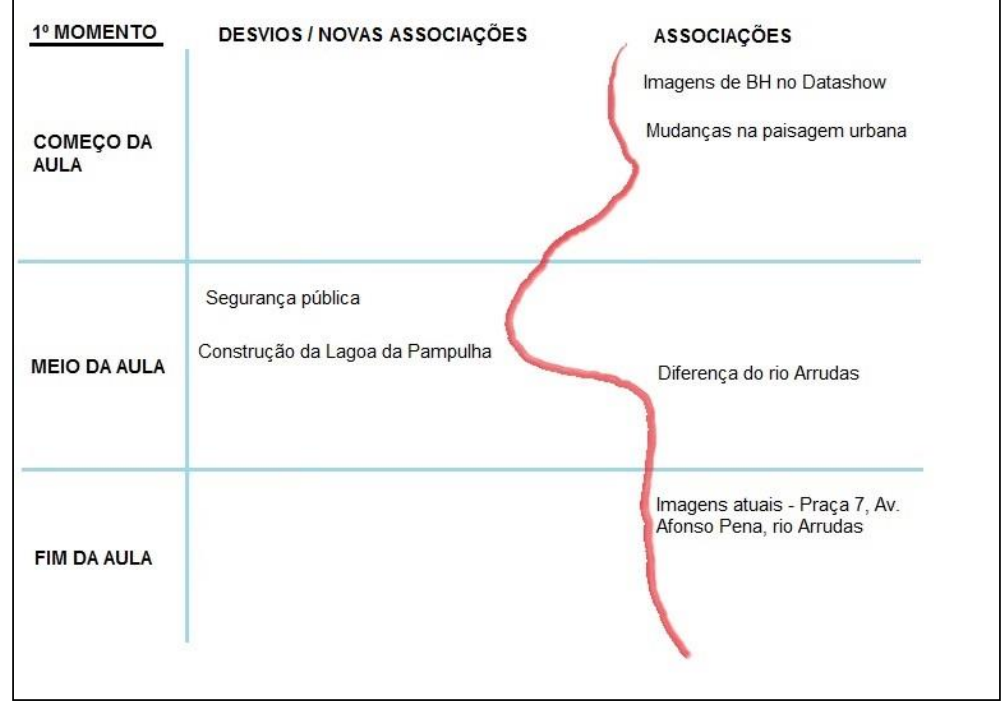

Fonte: os autores

Já no início da análise dessa aula demonstramos duas associações ocorridas entre os actantes que participaram dessa rede. A primeira delas relacionada ao uso do aparelho projetor de imagens, o Datashow, que favoreceu apresentar aos humanos um fenômeno que pode ser representado de forma oral ou escrita, ou seja, a partir das imagens os alunos perceberam as mudanças sofridas na paisagem (segunda associação) com o processo de urbanização. No decorrer da aula ocorreu um desvio, pois os alunos traçaram uma nova associação ao relatarem algo sobre segurança pública. Essa associação foi despertada logo quando foram expostas as imagens de lugares sem as grades que hoje definem a sua paisagem. Apesar de ser um assunto muito importante para o processo de construção e desenvolvimento urbano, esse não foi muito discutido.

No seguimento da aula, uma nova associação foi destacada, ainda que também tenha se desviado da proposta inicial, a construção da Lagoa da Pampulha. Essa não era uma associação prevista durante a construção dessa atividade, no entanto foram importantes para despertar a atenção dos estudantes sobre as transformações ocorridas na cidade, além de apresentar fatos, antes desconhecidos por eles. Em um próximo momento surge uma nova associação relacionadas às mudanças do rio Arrudas. Nesse 


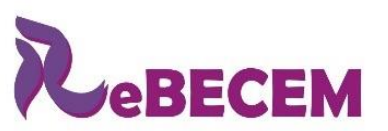

DOI: https://doi.org/10.33238/ReBECEM.2020.v.4.n.2.24220

momento todos os comentários e performance da rede giraram em torno das mudanças que vinham ocorrendo na cidade a partir da urbanização.

Ao refletir sobre esses dados, traçamos uma rede performada por essas entidades que evidencia um aprendizado estético (FLANNERY, 1999). Isto porque, a professora ao usar um híbrido (Datashow + imagens) propiciou a interação deste que operou uma ação sobre os alunos, causando-os um estranhamento pelo contato visual que tinham com as imagens. Os alunos manifestaram suas sensações e suas percepções expondo opiniões, dúvidas, contentamentos e descontentamentos a respeito do processo de urbanização de BH. Nesse sentido, a aprendizagem gerada foi performada por meio das translações proporcionadas ou uma ampliação da percepção dos sujeitos que se articulam com o ambiente de maneira diferenciada os remetendo a um passado que os permite entender o seu presente. Uma aprendizagem que se performa pelo processo de se deixar afetar e, portanto, se abre a possibilidade de estabelecer mais conexões com diferentes elementos que tornam este corpo que aprende mais articulado e diferenciado (LATOUR, 2004).

Quanto mais os alunos se envolviam com o Datashow e as imagens, mais eles se articulavam com esse híbrido, e possivelmente se abriam a uma percepção estética diferenciada sobre o mundo, que pode levar a um maior conhecimento, e consequentemente, um relacionamento mais profundo com o ambiente (FLANNERY, 1999). Ou seja, o contato das imagens de diferentes épocas, locais e fases de construção de Belo Horizonte podem favorecer o estreitamento entre as relações entre alunos e cidade, estimulando a manifestação de diferentes sentimentos, como por exemplo, ao de pertencimento em relação à região, podendo se desdobrar ao conhecimento de si mesmo. Acreditamos que a atividade proposta parece cumprir com seu objetivo inicial de estimular a curiosidade em relação aos processos de urbanização de determinado espaço ou região. As mudanças que eram ignoradas pela ausência de percepção e de um olhar interessado em seu próprio ecossistema (SOLER, 2016), passam ser integradas em uma rede que mobiliza afetações que podem expandir um corpo que se articula de maneira diferente com um ambiente que se transforma e o transforma (COUTINHO; GOULART; PEREIRA, 2017) 
DOI: https://doi.org/10.33238/ReBECEM.2020.v.4.n.2.24220

\subsection{Momento 2: Estudo do meio}

Essa foi a atividade mais importante da sequência didática e despertou interesse e motivação desde o início. Os alunos estavam ansiosos e sempre falavam nunca ter ido a um lugar assim, que nunca fizeram uma trilha, principalmente em atividade escolar. No trajeto até chegar à Estação Ecológica, o ônibus que levava o grupo passou perto de lugares dos quais tinha visto as imagens no momento anterior, e alunos fizeram comentários sobre o que haviam discutido acerca das transformações desses espaços ao longo do tempo.

Ao chegar na Estação Ecológica ${ }^{11}$ fomos recepcionados por uma monitora que nos acompanhou até a casa sede onde fica a administração da instituição. Devido ao tamanho, a turma foi dividida em dois grupos que seriam guiados por dois monitores durante a trilha. Um grupo foi acompanhado pela pesquisadora, e outro pela professora de inglês da escola que se ofereceu para ajudar. A turma da pesquisadora fazia várias perguntas e comentários, ainda que muitas vezes ignorados pela monitora. A monitora era estudante do curso de Engenharia Ambiental e procurava seguir o roteiro prédeterminado de visitas.

Ao aproximarmos da entrada da trilha a monitora perguntou aos alunos se eles já estudaram sobre os biomas do Brasil. Houve curto período de silêncio, até responderem que não, que nunca ouviram falar e outros que sim. Falavam ao mesmo tempo, um tentando convencer o outro de que aquele assunto já havia sido estudado. No entanto, para situá-los melhor, a monitora caracterizou os dois biomas que compunham aquele espaço, sendo a Mata Atlântica e o Cerrado.

Após sua breve explicação sobre os biomas, ela perguntou se os alunos conseguiam perceber qualquer diferença em relação a cidade, ou seja, ao que estava fora da entrada da trilha. A aluna Sara respondeu dizendo que "o local era mais silencioso e mais frio". Sem maiores questionamentos, a monitora deu continuidade após a fala da aluna, que o ambiente da estação abafava o som de fora devido o volume da vegetação, que o clima é mais agradável, porque a temperatura na estação ecológica é mais baixa também devido à presença de árvores. Os alunos não questionaram as informações e a

\footnotetext{
${ }^{11}$ A trilha visitada pertence a um espaço privilegiado da Universidade Federal de Minas Gerais, a Estação Ecológica (EEECO-UFMG). Essa unidade de conservação possui em média treze biótopos distribuídos em uma área de 114 hectares em que foram identificadas várias espécies de fauna e flora, incluindo nativas e exóticas.
} 
DOI: https://doi.org/10.33238/ReBECEM.2020.v.4.n.2.24220

monitora também não deu maiores explicações, concluindo o raciocínio com a justificativa da importância em manter as árvores da cidade.

O grupo entrou na trilha e a primeira parada era para mostrar uma espécie de aranha, conhecida como "aranha de funil", devido ao formato de sua teia. Os alunos demonstraram muita curiosidade, queriam ficar mais tempo observando, pois nunca ouviram falar ou tinham visto espécie semelhante. Curiosos para tentar ver o animal e entender o porquê de um formato tão diferente de teia, o aluno Caio perguntou: "Por que é assim a sua teia?" A monitora responde que a teia dela tem esse formato para facilitar a captura das presas e auxiliar na sua proteção. E o aluno indagou: 'Mas onde ela está? Não tô conseguindo ver”. A monitora disse que a aranha deveria estar no fundo da teia, mas repreendeu os alunos dizendo que não iríamos mexer, e os chamou para seguir a trilha.

A parada seguinte era próxima de uma árvore alta e cheia de espículas, a paineira. A monitora contou brevemente uma história dessa árvore chamando atenção para seu processo evolutivo da espécie e da preguiça gigante. Ela falou que a paineira era um dos alimentos preferidos da preguiça gigante, atualmente extinta, e que os espinhos eram uma forma de proteção da árvore. Ela descreveu resumidamente como a fibra produzida pela paina pode ser usada no preenchimento de travesseiros, pelúcias, colchões. Explicou que o crescimento da árvore é rápido, e por isso ela é utilizada em reflorestamentos e também na extração da celulose para produzir papel. Quando a aluna Vanessa perguntou: “Uai, mas a árvore não vem do papel?”. Todos os alunos repreenderam-na, rindo e contestando o que ela havia acabado de dizer. Foi unânime e todos os alunos disseram que o papel vinha da árvore e não o contrário. A aluna Sara ainda complementou: "Por isso que a gente deve economizar o papel, os cadernos, por que assim a gente cuida das árvores". Não fizeram mais comentários a respeito, e a monitora perguntou se havia alguma dúvida, como responderam negativamente seguimos adiante.

O terceiro ponto de parada era mais distante dos outros, alcançamos a região de transição entre o Cerrado e Mata Atlântica. A monitora pediu aos alunos que observassem ao seu redor e percebessem a diferença entre os dois biomas. Pouco depois, ela chamou a atenção para um casebre, já em ruínas contando a sua história e o motivo de sua presença naquele local. Foi quando o grupo foi surpreendido por um bando de micos que faziam a maior algazarra numa árvore bem próxima. Os micos foram a atração principal, e nada do que a monitora falava era ouvido pelos estudantes. 
DOI: https://doi.org/10.33238/ReBECEM.2020.v.4.n.2.24220

A monitora deu continuidade narrando mais sobre a história do casebre. Ela contou que antigamente a estação era uma fazenda que foi cedida para ser um lar de meninos no qual ficavam na casa sede. Aquele casebre tinha uma bomba para levar a água da nascente até a casa. Os alunos fizeram vários comentários sobre a casa de avós e outros parentes do interior, de roças, chamando atenção para a semelhança, que também havia bomba para trazer água de nascente etc. Foi quando a aluna Alice questionou se podíamos ir à nascente. Mas a monitora respondeu que não, pois o tempo não seria suficiente e seguimos adiante.

Na caminhada a monitora disse que o grupo entraria em uma região da trilha na qual encontraríamos muitos entulhos e explicou que antes de se tornar a estação ecológica o espaço era utilizado como bota fora. E, rapidamente, o aluno Caio questionou: "O que é bota fora?". "É uma região de descarte de entulhos de construções", respondeu a monitora, "neste caso, entulhos provenientes das obras da UFMG". Pelo caminho encontramos vários pedaços de azulejos, tijolos e outros materiais usados em construção.

$\mathrm{Na}$ parada seguinte, a monitora mostrou uma planta comum de cerrado conhecida como lobeira. Seu fruto é um dos alimentos preferidos do lobo guará. Ao falar do lobo guará, um dos alunos perguntou se esse animal aparecia na estação. A monitora respondeu que não, o espaço não abrigava animais de médio a grande porte e seguiu contando sobre a importância do lobo guará para a lobeira. Porém, os alunos estavam voltados para um buraco no tronco dessa árvore que abrigava um artrópode, aparentemente uma aranha, porém não foi possível identificá-la. Além disso, a monitora não parecia estar satisfeita por interrompê-la. A professora chamou a atenção para que se voltassem e que permitissem que a monitora concluísse sua fala. A monitora explicou que os lobos auxiliavam na perpetuação da lobeira pelo Cerrado, pois eles dispersavam suas sementes nas suas fezes.

Nesta mesma parada a monitora fez uma nova observação, indicando para um monte de terra já "petrificado". E perguntou aos alunos: "Vocês acham que isto é um cupinzeiro ou formigueiro?". A maioria respondeu formigueiro. Após ouvir as respostas dos alunos, a monitora disse que era um cupinzeiro e explicou a diferença dos dois para os estudantes, dizendo que a terra do formigueiro menos compacta em relação ao cupinzeiro. Permitiu que tocassem no cupinzeiro para sentirem a rigidez da terra. Ao sairmos desse ponto, no caminho para a penúltima parada localizamos um formigueiro e eles puderam atestar a diferença. 
DOI: https://doi.org/10.33238/ReBECEM.2020.v.4.n.2.24220

$\mathrm{Na}$ última parada havia uma grande árvore, a copaíba. A monitora explanou que dessa árvore extraia-se um óleo usado para fins medicinais. Neste momento, era notório o desinteresse dos alunos tomados pelo cansaço e fome. A monitora não delongou seu discurso e o grupo seguiu para as proximidades da casa sede, encaminhando os alunos para o local onde seria servido o lanche. Durante o lanche fomos surpreendidos pelos micos que nos rodeavam para roubar um petisco. Além dos jacus, espécie de ave, que se manteve bem próximo de onde estávamos.

A partir de nossas análises identificamos a trilha como um actante focal, pois, todo diálogo e interação entre os demais actantes obrigatoriamente conectaram-se por meio do caminho trilhado. Mantendo o padrão de análise, descrevemos a performance que emerge rede por meio da figura 3 :

Figura 3: Diagrama de translações: Trilha ecológica

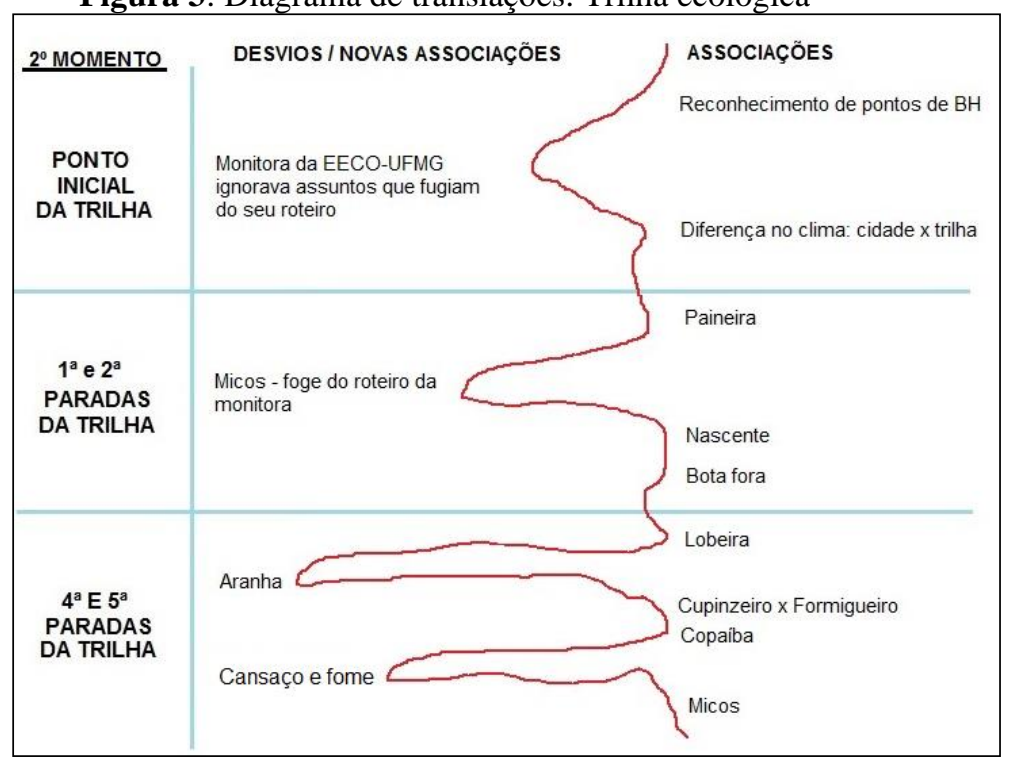

Fonte:os autores

No início da trilha apresentamos dois momentos de associações para um de desvio. A primeira associação feita é o reconhecimento de alguns pontos de Belo Horizonte durante o trajeto da escola até a trilha. Isso se deu a partir das imagens visualizadas na aula anterior. Essa associação é mais um indício de que na aula anterior houve um aprendizado estético (FLANNERY, 1999), uma vez que os alunos identificaram pontos da cidade, apenas com a experiência da aula anterior mediada por imagens.

A segunda associação feita é a percepção entre os climas fora e dentro da trilha. Essa experiência parece provocar um efeito na aprendizagem sobre a importância das árvores para a vida urbana. Na presença delas o clima se torna mais agradável. Essa 
DOI: https://doi.org/10.33238/ReBECEM.2020.v.4.n.2.24220

percepção só foi possível, pois os alunos tiveram uma experiência fora e dentro da trilha, assim eles sentiram e atestaram a diferença de temperatura e o frescor provocado pelo volume de árvores na mata. Mais um indício de aprendizado estético, pautada na percepção que visa relacionar a experiência com o conhecimento (LEOPOLD, 1949).

Em relação ao primeiro desvio identificado, este esteve associado aparentemente a formação acadêmica da monitora que guiava a turma. A medida que os actantes tentavam traçar novas associações, estas não se concretizavam uma vez que a monitora não flexibilizava seu roteiro. Em atividades de trilha guiada, a interação do monitor é de extrema importância para o desenvolvimento das afetações dos alunos. Essa interação propicia a mobilização de mais actantes, o que favorece novas translações.

\footnotetext{
Isso porque, quanto mais mediações existem, se torna mais fácil adquirir um corpo que seja sensível aos efeitos de mais entidades diferentes. Para resumir em um vocabulário latouriano: quanto mais translações, mais o mundo se torna vasto (COUTINHO; GOULART; PEREIRA., 2017.p.9).
}

Portanto, em uma perspectiva latouriana quanto mais um indivíduo interage com seu entorno, mais ele se torna diferenciado (MELO, 2011), ou seja, seu corpo é afetado pelas associações entre os elementos da trilha. Do mesmo modo, a monitora, enquanto mediadora dessa rede, teve uma atuação que limitou as interações dos estudantes com o meio, nos fazendo refletir sobre a estratégia de fazer a trilha de forma guiada. Talvez se os alunos estivessem orientados para investigar, poderiam trazer mais elementos daquele cenário socioambiental para a rede, expandindo-a, transformando a própria atividade de aprendizagem (COUTINHO; MATOS; RODRIGUES E SILVA, 2014).

No diagrama é possível visualizar novas associações quando a monitora faz a parada em frente a paineira. Os actantes, alunos e monitora se conectaram a outros elementos que não faziam parte da trilha, mas necessários à explicação da presença de grandes espículas espalhadas pelo seu tronco. Nesse momento a monitora faz um resgaste da pré história, introduzindo novos actantes na rede, como a preguiça gigante, atualmente extinta. A preguiça gigante performou a rede para dar sentido a presença das espículas da paineira. As espículas tinham a função de proteção contra as garras da preguiça que tinha a paineira como seu alimento preferido. Desse ponto a rede deslocou-se para produção de papel. A monitora informou que essa árvore também era utilizada pelas indústrias de extração de celulose, pois é uma planta que tem o crescimento rápido, mostrando-se eficiente também para áreas de reflorestamento.

Apesar da monitora apresentar pouca afetividade com os alunos e não flexibilizar o seu roteiro de caminhada, ela pode ser identificada como um mediador, 
DOI: https://doi.org/10.33238/ReBECEM.2020.v.4.n.2.24220

uma vez que possui a capacidade de redefinir o que transporta, ou seja, seu conhecimento que transforma e muda continuamente as relações entre as entidades, fazendo com que estas realizem coisas, associações ou interações (LATOUR, 1994). Seguido dessas associações, a atividade sofre uma nova associação, que fugia do roteiro definido pela monitora. Enquanto ela direcionavaa seus conhecimentos sobre o casebre que bombeava água da nascente até a casa sede, vários micos atraíam a atenção dos alunos fazendo uma verdadeira algazarra. Para os alunos esse momento foi descontraído e importante para o processo de aprendizado, pois viam os micos interagindo com o ambiente conhecendo um pouco sobre o comportamento desses animais. A monitora, chamou atenção dos alunos para que se concentrassem nas informações passadas sobre a casa sede e a rede se desloca e performa para o sentido em que a monitora previa com seu roteiro. Uma nova associação foi traçada quando a monitora citou a nascente. Os alunos pediram para vê-la, o que não foi autorizado pela monitora com a justificativa de falta de tempo. Ainda assim, os alunos mobilizaram seus conhecimentos sobre nascente e fizeram vários comentários sobre a existência ou desaparecimento nas roças de parentes. Mas o assunto foi dispersado mostrando que a nascente atuou como um actante intermediário.

Seguindo a trilha houve nova associação, dessa vez com o chamado bota fora. A monitora contou que, antes do espaço ser protegido como uma estação ecológica, era destinado ao descarte de entulhos. Nesse momento os alunos puderam observar restos de cerâmica pela trilha, mas novamente tivemos uma associação que não mobilizou outros conhecimentos e não causou nenhuma tranformação.

Nas últimas paradas da trilha, uma nova associação é traçada e outro actante passa a compor essa rede, a lobeira. Esse actante carrega a existência do lobo guará que se alimenta de seu fruto e contribui para dispersar suas sementes. Essa associação performou a rede para o modo de vida e habitat do lobo guará. A partir da lobeira também houve um desvio, nesse caso a presença de um animal que fazia de seu tronco, proteção. Não era possível identificar o animal, mas aparentemente uma aranha, esse desvio causou novamente desconforto para a monitora que foi interrompida na tentativa de desviar do seu roteiro. Porém, a monitora chama atenção novamente para outro elemento introduzindo na rede novos actantes, formigueiro e cupinzeiro. Estes se associaram aos demais actantes e mobilizaram conhecimentos que eles já possuíam a partir de suas experiências. Para eles, todos os montes de terra eram formigueiros. A monitora, como actante mediador, transformou os actantes alunos mostrando-os a 


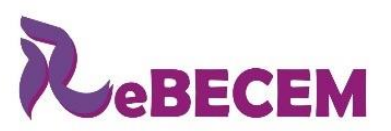

DOI: https://doi.org/10.33238/ReBECEM.2020.v.4.n.2.24220

diferença entre os dois elementos formigueiro x cupinzeiro. Ao seguir a trilha, a cada "monte de terras" iam sendo identificados como formigueiro e como cupinzeiros.

Já na fase final houve nova associação com a introdução de novo actante, a copaíba. A monitora trouxe elementos medicinais para compor mais uma vez a rede e performá-la dando sentido a extração do óleo de copaíba. Sob o olhar da TAR percebemos que a copaíba atuou como actante intermediário já que o assunto se dispersou rapidamente sem gerar nova associação. Esse momento foi seguido de um desvio motivado pelo cansaço e pela fome. Esses dois elementos dispersaram a atenção e motivação dos alunos o que não favorecia novas translações. Com a saída da trilha mais uma vez fomos surpreendidos pelos micos, que rapidamente despertaram atenção dos alunos gerando uma nova associação que perdurou até a saída da estação ecológica.

Podemos perceber que a atividade de trilha se apresenta com vários potenciais para aprendizagem, principalmente a estética. Esse fato é justificado pelo fato de que durante a trilha houve interação, motivação e interesse dos alunos sobre os diversos assuntos tratados. Além de gerar momentos de experiência associadas à percepção do ambiente natural. Ainda que a atividade possa ter sofrido momentos de desvios ou associações inesperadas, estes foram importantes para as translações ocorridas e consequente performance da rede.

\section{Considerações finais}

A nossa investigação teve como ponto de partida o interesse em pesquisar a aprendizagem de um grupo de alunos do Ensino Fundamental II a partir de uma sequência didática que tinha como atividade principal uma saída de campo para uma trilha ecológica. Em princípio, a nossa grande preocupação era a de entender como diferentes elementos socioamebintais contribuíam para a aprendizagem de conceitos associados aos conteúdos referentes à temas ambientais. Era nossa expectativa inicial que os diferentes actantes mobilizados propiciassem uma compreensão sobre elementos conceituais que são trabalhados nas aulas de ciências.

Para a construção da SD, nós escolhemos diferentes atividades que envolviam a leitura de textos de capítulos de livros, a exposição e análise de imagens, a pesquisa em campo, a visita à uma estação ecológica. Essa pluralidade de atividades foi pensada para favorecer uma aprendizagem mais ampla, mas entre o que foi idealizado e o que foi possível fazer existiu uma grande diferença. 
DOI: https://doi.org/10.33238/ReBECEM.2020.v.4.n.2.24220

Entretanto, se esperávamos ter dados referentes a uma aprendizagem de natureza conceitual, nos vimos em uma situação de frustração de expectativas. Ao analisar os dados, não observamos a enunciação de conceitos científicos, de proposições de explicações ou argumentos bem fundamentados. Em um primeiro momento, ao elaborar os nossos diagramas de associações, identificamos diferentes actantes mobilizados pelos alunos que foram considerados desvios, entretanto só foram identificados dessa forma à luz das nossas expectativas iniciais. Expectativas que se originam de nossa prática docente, muitas vezes, marcada por um olhar mais restrito do que entendemos como aprendizagem. Em uma análise mais detida e fundamentada fortemente na Teoria AtorRede, que nos incita a abandonar as nossas hipóteses e nos lançar ao desconhecido (LATOUR, 2012), podemos observar que os actantes presentes nessas redes nos levaram a associações inesperadas que evidenciaram outras vivências ou performances.

Em uma análise geral, acreditamos que as atividades propostas, principalmente a trilha ecológica, favoreceu uma aprendizagem que podemos associar à estética. Nesse sentido, temos em nossa pesquisa dados que evidenciam que as experiências visuais, tanto com as imagens de Belo Horizonte, quanto com a trilha oportunizaram novas e importantes associações que se materializam por meio de sensações e sentimentos expressos por esses alunos.

A partir de uma abordagem latouriana, podemos concluir que a aprendizagem estética, pouco valorizada nos processos de ensino de Ciências e Biologia, pode contribuir para a educação científica ampliando as percepções e as vivências dos alunos. Novamente voltamos a assumir que a aprendizagem consiste em estabelecer translações com os diferentes actantes e dessa forma se articular e se deixar afetar, o que incide em perceber o mundo em diferentes dimensões, inclusive de modo estético. Consideramos que a SD proposta e a que foi aplicada promoveu essa aprendizagem estética. Esse é um resultado, a princípio, inesperado, mas que nos traz uma nova associação com a Filosofia da Estética que pode nos trazer contribuições para discussões futuras.

\section{Referências}

ALLAIN. L. R. Mapeando a identidade profissional de licenciandos em Ciências

Biológicas: um estudos Ator-Rede a partir do programa institucional de bolsa de iniciação a docência. 2015. Tese (Doutorado em Educação em Ciências) - Universidade Federal de Minas Gerais - UFMG, Belo Horizonte, 2015. 
DOI: https://doi.org/10.33238/ReBECEM.2020.v.4.n.2.24220

CALLON, M. Some elements of a sociology of translation: domestication of the scallops and the fishermen of Saint Brieuc Bay. In: Law, J. Power, Action and Belief. A New Sociology of Knowledge?, Boston: Routledge, 1986, p. 196-233.

CARO, C. M. et al. Construindo Consciências: Ciências, $7^{\circ}$ ano. São Paulo: Scipione, 2009.

COUTINHO, F. A.; MATOS, S. A.; SILVA, F. A. R. Aporias dentro do movimento Ciências, Tecnologia, Sociedade e Ambiente. Apontamentos para uma solução. Revista Sociedade Brasileira do Ensino de Biologia - SBEnBio, São Paulo, n. 7, out. 2014.

COUTINHO, F. A.; GOULART, M. I. M.; PEREIRA, A. F. Aprendendo a ser afetado: contribuições para a educação em ciências na educação infantil. Educação em revista, Belo Horizonte, v. 33, e155748, 2017.

COUTINHO, F. A.; VIANA, G.M. Teoria ator-rede e educação. Curitiba: Editora Appris, 2019.

FARIA, E. S.; COUTINHO, F. A. Educação científica em ação: a cartografia de controvérsias como prática de cidadania técnico-científica. Cadernos de Pesquisa, v. 22, n. 3, p. 133-147, 2015.

FENWICK, T.; EDWARDS, R. Researching education through actor-network theory. John Wiley \& Sons, New Jersey, 2012.

FLANNERY, M. C. The conservation aesthetic and the microscopic aesthetic. Bioscience, Oxford, v. 49, n. 10, p. 801-808, 1999

FREIRE, L. L. Seguindo Bruno Latour: notas para uma antropologia simétrica. Comum, Rio de Janeiro, v. 11, n. 26, p. 46-65, 2006.

LATOUR, B. Jamais Fomos Modernos. Rio de Janeiro, RJ: Ed. 34.1994.

LATOUR, B. How to Talk About the Body? The Normative Dimension of Science Studies. Body \& Society, Califórnia: Sage, v. 10, n. 2-3, p. 205-229, 2004.

LATOUR, B. Reagregando Social: uma introdução a teoria do Ator - Rede. Bauru, SP: EDUSC, 2012.

LAW, J. Notes on the theory of the actor-network: Ordering, strategy, and heterogeneity. Systems practice, Berlim, v. 5, n. 4, p. 379-393, 1992.

LEOPOLD, A. A Sand County Almanac and Sketches Here and There. Oxford UniversityPress. New York, 1949.

LESTINGE, S.; SORRENTINO, M. As contribuições a partir do olhar atento: estudos do meio e a educação para a vida. Ciência \& Educação, Bauru, v.14, n.3, p. 601-619, 2008.

LOPES, C.; PONTUSCHKA, N. N. Estudo do Meio: teoria e prática. Revista Geografia, Londrina, v. 18, n. 2, p. $173-191,2009$.

MELO, M. F. A. Q. A aprendizagem sob a perspectiva da teoria ator - rede. Educar em Revista, Curitiba, n. 39, p. 177 - 190, 2011. 
DOI: https://doi.org/10.33238/ReBECEM.2020.v.4.n.2.24220

PEDRETTI, E.; NAZIR, J. Currents in STSE education: mapping a complex field, 40 years on. Science Education, New Jersey, v. 95, p. 601-626, 2011.

SANTOS, P. G. F. et al. A abordagem de questões científicas no ensino de ciências: uma compreensão de sequências didáticas propostas por pesquisas na área. In: ENCONTRO NACIONAL DE PESQUISA EM EDUCAÇÃO EM CIÊNCIAS, 8, 2011, Campinas, SP, Anais do VIII Encontro Nacional de Pesquisa em Educação em Ciências. Campinas, 2011.

SANTOS, F. C. Sequência didática para o ensino fundamental: trilhas para investigar a aprendizagem em ambientes naturais e urbanos. 2017. Dissertação (Mestrado em Ensino de Ciências) - Instituto de Ciências Exatas e Biológicas, Universidade Federal de Ouro Preto, Ouro Preto, 2017.

SAYES, E. Actor Network Theory and methodology: Just what does it mean to say that nonhumans have agency? Social Studies of Science, Kingston, v. 44, n.1, p. 134-149, 2014.

SILVA, L. F.; CARVALHO, L. M. A temática ambiental e o processo educativo: o ensino de física a partir de temas controversos. Ciências \& Ensino, v. 1, n. especial, 2007.

SILVA, R. L.; ARAUJO-QUEIROZ, M. B.; PRUDÊNCIO, C. A. V. CTS ou CTSA: o que (não) dizem as pesquisas sobre Educação Ambiental e Meio Ambiente? ALEXANDRIA, Florianopolis, v. 12, p. 31-54, 2019

SILVEIRA JUNIOR, C.; LIMA, M.E.C. C; MACHADO, A. H. Leitura em sala de aula de ciências como uma prática social dialógica e pedagógica. Ensaio: Pesquisa em Educação em Ciências, Belo Horizonte, v. 17, n. 3, p. 633-656, dez. 2015

SOLER, A. Água e urbanização na cidade de São Paulo: uma proposta de ensino para o ensino fundamental II. 2016. Dissertação (Mestrado em Educação) - Faculdade de Educação, University of São Paulo, São Paulo, 2016.

SOUZA, V. T. de. et al. Trilhas interpretativas como instrumento de Educação Ambiental. Ensino, Saúde e Ambiente, v. 5, n. 2, p. 294-304, ago. 2012.

Recebido em: 26 de fevereiro de 2020

Aceito em: 20 de julho de 2020 